\title{
Assessment of Knowledge, Qualification, Experience, and Medication Dispensing Practices in South Karachi, Pakistan
}

\begin{abstract}
Nauman Haider Siddiqui ${ }^{1}$, Abdullah Dayo ${ }^{1}$, Mudassar Iqbal Arain ${ }^{2}$, Muhammad Ali Ghoto ${ }^{2}$, Saira Shahnaz ${ }^{3}$, Ramesha Anwar ${ }^{4}$, and Jibran Khan ${ }^{1}$

${ }^{1}$ Department of Pharmaceutics, Faculty of Pharmacy, University of Sindh, Jamshoro, Pakistan

${ }^{2}$ Department of Pharmacy Practice, Faculty of Pharmacy, University of Sindh, Jamshoro, Pakistan

${ }^{3}$ Department of Pharmacy Practice, Faculty of Pharmacy, Nazeer Hussain University, Karachi, Pakistan

${ }^{4}$ Department of Pharmacy Practice, Faculty of Pharmacy, University of Karachi, Karachi, Pakistan
\end{abstract}

ORCID:

Nauman Haider Siddiqui: http://orcid.org/0000-0002-1797-9927

\section{Abstract}

Background: Drug stores in Pakistan are run by dispensers with varied knowledge,

Corresponding Author: Nauman Haider Siddiqui; Department of Pharmaceutics, Faculty of Pharmacy, University of Sindh, Jamshoro.

email: mudassarpk@live.com

Received 14 March 2021

Accepted 22 May 2021

Published 30 June 2021

Production and Hosting by Knowledge E

(c) Nauman Haider Siddiqui et al. This article is distributed under the terms of the

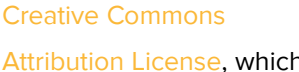

permits unrestricted use and redistribution provided that the original author and source are credited.

Editor-in-Chief:

Prof. Mohammad A. M. Ibnouf qualification, and experience. The current study was sought to explore the knowledge, qualification, experience, and dispensing practices among dispensers working in drugstores in South Karachi, Pakistan.

Methods: A cross-sectional survey was carried out using a structured questionnaire. Data were collected from medical stores in South Karachi which were then categorized, coded, and analyzed using SPSS version 23. Relationship among different study variables with pharmacist's availability and personal experience was assessed using statistical non-parametric Chi-square test. A total of 385 samples obtained using a simple random sampling method were included in the study. However, only 210 responses on questionnaire were complete which were then selected for study analysis between October and December 2018.

Results: Of the 210 surveyed drugstores, $9 \%$ of their staff had studied only till primary school, $5.7 \%$ till the eighth grade, $25.2 \%$ up to secondary school level, $26.7 \%$ till higher secondary school level, $15.7 \%$ had non-professional education, and $8.1 \%$ were professional graduate. Only 9\% of them had a degree in Pharm. D or B. Pharm, while $0.5 \%$ had a post-graduation qualification. Furthermore, $44.8 \%$ of pharmacies had a valid pharmacy license but the pharmacist was physically absent in $91 \%$ of the drugstores. Majority of pharmacies did not maintain appropriate temperature (refrigerator and/or room temperature). Majority of dispensers did not review prescription particulars before dispensing medications and also dispensed medications on older prescriptions as well as without prescription.

Conclusion: In conclusion, the overall knowledge and practices of dispensers working in drugstores was poor. However, the presence of pharmacist was associated with good dispensing practices to a certain extent.

Keywords: community pharmacy, good dispensing practice, pharmacist, prescription

\section{G OPEN ACCESS} review 


\section{Introduction}

Pharmacy services begin with prescription of medicines and continues till its dispensing and as medication's effect is monitored [1]. Good dispensing practices ensure that an effective form of correct drug is provided to the right patient, in correct dose and number of units, with clear instructions, and in a package that maintains the potency of drug. Dispensing also incorporates all of actions that befall between the time prescription is dropped to pharmacy and the time when medication or other articles prescribed are delivered [2].

In Pakistan, medications-use patterns vary among gender and age groups. Selfmedication and polypharmacy are frequent amid the youth and elderly population, respectively [3-7]. Likewise, the self-use of analgesics and antipyretics is very common among youth [3-5]. Systematized dispensing practices are disregarded in community pharmacies as well as in hospitals [8]. Unfortunately, majority of the drug dispensing at pharmacies and medical stores is carried out by untrained dispensers with no proper qualification in pharmacy. In such circumstances, there is a serious need to ensure the presence of a qualified pharmacist at all retail pharmacies so that the medications are safely dispensed $[9,10]$. Lack of physicians in the rustic regions has created an opportunity for the dispensers and quacks to fill the gap where they are the only decision-makers of the medications for the public [11]. Furthermore, patients have to cover long distances to acquire basic medications. Additionally, most of the medications can be purchased from private pharmacies without showing a legal prescription $[3,12$, 13]. A study carried out in Pakistan stated that numerous dispensers have irrelevant education and negligible or no competent training in managing drugstores [14]. Provided that with inadequate knowledge concerning indications, contraindications, as well as side effects, their dispensing practices might have unwanted outcomes.

Although a system of healthcare facilities exists in Pakistan's public division as well as an overabundance of private division programs, $45 \%$ of people still face paucities to approach to healthcare facilities. However, to encounter healthcare necessities and decrease personal costs, people depend on unconventional healthcare systems such as chemists, contemporary medication specialists, faith healers, and homeopaths. Huge disparities in formal healthcare division promote self-medication; therefore, knowledge as well as practices of dispensers become significantly valuable [15]. Drugstores in developing countries like Pakistan are frequently deficient of competent and trained dispensers to store, label, and handle medicines in suitable manner which may compromise drug safety and its therapeutic outcomes. Therefore, the current study was sought 
to explore the dispensing practices in medical stores/pharmacies in Pakistan and to investigate the implementation of laws and regulations regarding selling, storage, and dispensing of medications.

\section{Materials and Methods}

A cross-sectional survey was carried out using a structured questionnaire. The structured questionnaire was developed from the WHO surveillance form designed for perceiving medicine counselling and dispensing practices and was customized in accordance with the aims of this study [16]. Data were collected from pharmacies/medical stores of South Karachi. The city of Karachi is divided into six districts, South, Central, West, East, Korangi, and Malir. The southern district of Karachi has the distinction of being the only district in the country with a representation of all ethnic and socioeconomic groups of the country [17]. The present study was conducted between October and December 2018 and included 384 samples obtained through simple random sampling method. The accuracy and consistency of data collection form was assessed in a pilot study of 20 pharmacies. Each pharmacy was observed for one day. The response of pharmacies to participate in study was also estimated to calculate the sample size. The standardized questionnaire was tested on 30 participants before the actual data collection and it was modified into a list of questions that were comprehensive and unambiguous. A predesigned and pretested survey in English language was utilized to collect responses. A total of 385 samples were included in the study. The sample size was obtained using a simple random sampling method, out of which 210 responses on questionnaire were complete and selected for study analysis. Conversely, those who did not understand English were questioned by researcher in local Urdu and the answers were then translated into English. We used paper-based questionnaire. The structured questionnaire consisted of 33 questions containing information on demographics, level of education, experience, temperature control information, dispensing practices, presence of pharmacist, and status of pharmacy licensing. Only participants who met the following criteria were included: male or female irrespective of age, retailers who were involved in the pharmaceutical drug sales, owner as well as employee in pharmacy, participant with any qualification and/or level of education with zero to any number of years of experience, pharmacies/medical stores in southern region of Karachi involved in drug dispensing. Conversely, participants who met the following criteria were excluded: wholesalers and distributors, retailers associated with sales other than pharmaceutical drugs, all inadequately filled questionnaires, pharmacies/medical stores 
located in other areas than the South of Karachi, participants working in store/stock management and administrative positions. Data collected in the form of completed questionnaires were then categorized, coded, and analyzed. They were expressed as percentages and frequencies. The relationship among different study variables with pharmacists' availability was assessed using a statistical non-parametric Chi-square test at 0.05 level of significance with the help of SPSS version 23 .

\section{Results}

Table 1 indicates the demographics of study participants. It was observed that $3.8 \%$ of the questionnaire respondents were female while $96.2 \%$ were male; $9 \%$ of the participants had only studied till primary school, 5.7\% till the eighth grade, $25.2 \%$ were qualified up to secondary school level, $26.7 \%$ till higher secondary school level, $15.7 \%$ had nonprofessional education, and $8.1 \%$ were professional graduate. However, only $9 \%$ of them had a degree in Pharm. D or B. Pharm, while $0.5 \%$ had a postgraduation qualification. Furthermore, $74.3 \%$ were employed in pharmacy and $25.7 \%$ were the owner of the pharmacy.

TABLE 1: Demographics of study participants.

\begin{tabular}{lc} 
Gender & \\
Male & $96.2 \%(202)$ \\
\hline Female & $3.8 \%(8)$ \\
\hline Education & \\
\hline Primary school & $9 \%(19)$ \\
\hline Till the eighth grade & $5.7 \%(12)$ \\
\hline Secondary school & $25.2 \%(53)$ \\
\hline Higher secondary school & $26.7 \%(56)$ \\
\hline Non-professional graduation & $15.7 \%(33)$ \\
\hline Professional graduation & $8.1 \%(17)$ \\
\hline Pharm. D or B. Pharm & $9 \%(19)$ \\
\hline Postgraduation & $0.5 \%(1)$ \\
\hline Employment status & \\
\hline Employed & $74.3 \%(156)$ \\
\hline Owner & $25.7 \%(54)$ \\
\hline Work experience (yr) & \\
\hline$<1$ & $41 \%(86)$ \\
\hline $1-3$ & $17.1 \%(36)$ \\
\hline $4-6$ & $23 \%(48)$ \\
\hline$>6$ & $19 \%(40)$ \\
\hline
\end{tabular}


Table 2 shows the figures of medication storage conditions, power backup, pharmacy license, and availability of pharmacy. While $44.8 \%$ of pharmacies had a valid pharmacy license, 55.2\% did not. Also, a pharmacist was physically absent in 91\% of the pharmacies and present only in $9 \%$. Furthermore, $72.4 \%$ of pharmacies did not maintain the recommended temperature for medicines that need to be refrigerated (i.e., $2-8^{\circ} \mathrm{C}$ ), only $27.6 \%$ maintained refrigerator temperature. It was observed that $57.6 \%$ of the pharmacies did not maintained room temperature (i.e., $25^{\circ} \mathrm{C}$ ) but $42.4 \%$ of them did.

TABLE 2: Medication storage conditions, power backup, pharmacy license, and availability of pharmacy.

\begin{tabular}{|c|c|}
\hline \multicolumn{2}{|c|}{ Valid license for pharmacy } \\
\hline Yes & $44.8 \%(94)$ \\
\hline No & $55.2 \%(116)$ \\
\hline \multicolumn{2}{|c|}{ Physical presence of a pharmacist } \\
\hline Yes & 9\% (19) \\
\hline No & 91\% (191) \\
\hline \multicolumn{2}{|c|}{ Power backup } \\
\hline Yes & $27.6 \%(58)$ \\
\hline No & $72.4 \%(152)$ \\
\hline \multicolumn{2}{|c|}{ Refrigerator temperature maintained $\left(2-8^{\circ} \mathrm{C}\right)$} \\
\hline Yes & $27.6 \%(58)$ \\
\hline No & $72.4 \%(152)$ \\
\hline \multicolumn{2}{|c|}{ Room temperature maintained $\left(25^{\circ} \mathrm{C}\right)$} \\
\hline Yes & $42.4 \%(89)$ \\
\hline No & $57.6 \%(121)$ \\
\hline
\end{tabular}

Table 3 reveals the dispensing practices observed in pharmacies. It shows that 91.9\% of study participants did not review prescription particulars before dispensing medications. Only $8.1 \%$ of them responded that they reviewed prescription particulars before dispensing medications. Furthermore, $18.1 \%$ did not dispense medications without prescription, while $81.9 \%$ of them did so. While dispensing medications on old prescriptions was observed in $81.9 \%$ of the participants, only $18.1 \%$ did not do so. Medication categories dispensed without prescription included OTC (41.4\%), antibiotics (16.7\%), analgesics (6.2\%), antidiabetic (5.7\%), anti-allergy (5.2\%), antidiarrheal (3.3\%), cough syrups (7.1\%), antihypertensive (4.3\%), and others (10\%). It was also noted that $31 \%$ of the participants did not dispense herbal medications while $69 \%$ did so. Alternative brands were not suggested in by $91.9 \%$ of the study participants while $8.1 \%$ of them dispensed alternative brands in case of nonavailability of the prescribed brand. Furthermore, $59.5 \%$ of the study participants did not confirm the expiry date of the medicine before dispensing while $40.5 \%$ of them did so. 
TABLE 3: Dispensing practices observed in pharmacy.

\begin{tabular}{|c|c|}
\hline \multicolumn{2}{|c|}{ Reviewing prescription particulars before dispensing } \\
\hline Yes & $8.1 \%(17)$ \\
\hline No & $91.9 \%(193)$ \\
\hline \multicolumn{2}{|c|}{ Dispensing without prescription } \\
\hline Yes & $81.9 \%(172)$ \\
\hline No & $18.1 \%(38)$ \\
\hline \multicolumn{2}{|c|}{ Medicine categories dispensed without prescription } \\
\hline ОTC & $41.4(87)$ \\
\hline Antibiotic & $16.7(35)$ \\
\hline Analgesic & $6.2(13)$ \\
\hline Antidiabetic & $5.7(12)$ \\
\hline Anti-allergy & $5.2(11)$ \\
\hline Antidiarrheal & $3.3(7)$ \\
\hline Cough syrups & $7.1(15)$ \\
\hline Antihypertensive & $4.3(9)$ \\
\hline Others & $10(21)$ \\
\hline \multicolumn{2}{|c|}{ Dispensing of herbal medicines } \\
\hline Yes & $69 \%(145)$ \\
\hline No & $31 \%(65)$ \\
\hline \multicolumn{2}{|c|}{ Dispensing medicines on older prescriptions } \\
\hline Yes & $81.9 \%(172)$ \\
\hline No & $18.1 \%(38)$ \\
\hline \multicolumn{2}{|c|}{ Dispensing alternative brands in case of nonavailability of prescribed brand } \\
\hline Yes & $8.1 \%(17)$ \\
\hline No & $91.9 \%(193)$ \\
\hline \multicolumn{2}{|c|}{ Expiry date confirmation before dispensing } \\
\hline Yes & $40.5 \%(85)$ \\
\hline No & $59.5 \%(125)$ \\
\hline
\end{tabular}

Table 4 shows awareness of participants regarding various essentials of pharmacy practice. It was found that $51.9 \%$ of the participants were not aware of abbreviations used in prescription. However, only $20 \%$ of the study participants were aware of $\leq 25 \%$ of abbreviations, $11 \%$ of $25-50 \%$ of abbreviations, $10.5 \%$ of $50-75 \%$ of abbreviations, and only $6.7 \%$ were aware of $>75 \%$ of abbreviations. Furthermore, only $8.1 \%$ of the study participants were aware of various schedules of medicines. Awareness of participants regarding pregnancy categories of medicines was also quite low, that is, only $9 \%$. Awareness of participants regarding various look-alike and sound-alike medicines was also unsatisfactory, that is, only 35.2\%. Similarly, participant's awareness regarding generic medicines, drug recall, adverse drug reactions, and life-saving medicines was $31,35.2,11.9$, and $41.4 \%$, respectively. 
TABLE 4: Awareness regarding various essentials of pharmacy practice.

\begin{tabular}{|c|c|}
\hline \multicolumn{2}{|c|}{ Awareness of various abbreviations used in prescriptions } \\
\hline Awareness of no abbreviations & $51.9 \%(109)$ \\
\hline $\begin{array}{l}\text { Awareness of } \leq 25 \% \text { of the } \\
\text { abbreviations }\end{array}$ & $20 \%(42)$ \\
\hline $\begin{array}{l}\text { Awareness of } 25-50 \% \text { of the } \\
\text { abbreviations }\end{array}$ & $11 \%(23)$ \\
\hline $\begin{array}{l}\text { Awareness of } 50-75 \% \text { of the } \\
\text { abbreviations }\end{array}$ & $10.5 \%(22)$ \\
\hline $\begin{array}{l}\text { Awareness of }>75 \% \text { of the } \\
\text { abbreviations }\end{array}$ & $6.7 \%(14)$ \\
\hline \multicolumn{2}{|c|}{ Awareness of various schedules of medicines } \\
\hline Yes & $8.1 \%(17)$ \\
\hline No & $91.9 \%(193)$ \\
\hline \multicolumn{2}{|c|}{ Awareness of pregnancy category of medicines } \\
\hline Yes & $9 \%(19)$ \\
\hline No & $91 \%(191)$ \\
\hline \multicolumn{2}{|c|}{ Awareness of various look-alike and sound-alike medicines } \\
\hline Yes & $35.2 \%(74)$ \\
\hline No & $64.8 \%(136)$ \\
\hline \multicolumn{2}{|l|}{ Awareness of generic medicines } \\
\hline Yes & $31 \%(65)$ \\
\hline No & $69 \%(145)$ \\
\hline \multicolumn{2}{|l|}{ Awareness of drug recall } \\
\hline Yes & $35.2 \%(74)$ \\
\hline No & $64.8 \%(136)$ \\
\hline \multicolumn{2}{|c|}{ Awareness of adverse drug reactions } \\
\hline Yes & $11.9 \%(25)$ \\
\hline No & $88.1 \%(185)$ \\
\hline \multicolumn{2}{|c|}{ Awareness of lifesaving medicines } \\
\hline Yes & $41.4 \%(87)$ \\
\hline No & $58.6 \%(123)$ \\
\hline
\end{tabular}

Table 5 reveals relationship among different study variables with pharmacist availability. Chi-square test was applied at 0.05 level of significance to check the association of different variables with the availability of a pharmacist at a drug store. It was found that there is a significant relationship between the presence of power backup at pharmacies, refrigerator temperature maintenance, room temperature maintenance, reviewing prescription particulars before dispensing, dispensing alternative brands in case of nonavailability of prescribed brand, and expiry date confirmation before dispensing and the availability of a pharmacist at a drug store at 0.000 (two-tailed). The level of significance and variables such as dispensing without prescriptions and dispensing on 
older prescriptions had no significant relationship with the presence and availability of pharmacist at a drug store.

TABLE 5: Cross-tabulation of variables.

\begin{tabular}{|c|c|c|c|}
\hline \multirow{3}{*}{$\begin{array}{l}\text { Variables } \\
\text { Power backup }\end{array}$} & \multicolumn{3}{|c|}{ Pharmacist availability } \\
\hline & \multicolumn{2}{|c|}{ Pharmacist present } & \multirow{2}{*}{$\begin{array}{c}\text { Pharmacist absent } \\
41\end{array}$} \\
\hline & Yes & 17 & \\
\hline & No & 2 & 150 \\
\hline \multicolumn{2}{|l|}{$P$-value } & \multicolumn{2}{|l|}{0.000} \\
\hline \multirow{2}{*}{$\begin{array}{l}\text { Refrigerator temperature } \\
\text { maintenance }\end{array}$} & Yes & 17 & 41 \\
\hline & No & 2 & 150 \\
\hline \multicolumn{2}{|l|}{$P$-value } & 0.000 & \\
\hline \multirow{2}{*}{$\begin{array}{l}\text { Room temperature } \\
\text { maintenance }\end{array}$} & Yes & 19 & 70 \\
\hline & No & 0 & 121 \\
\hline \multicolumn{2}{|l|}{$P$-value } & \multicolumn{2}{|l|}{0.000} \\
\hline \multirow{2}{*}{$\begin{array}{l}\text { Reviewing prescription } \\
\text { particulars before dispensing }\end{array}$} & Yes & 17 & 2 \\
\hline & No & 0 & 191 \\
\hline \multicolumn{2}{|l|}{$P$-value } & 0.000 & \\
\hline \multirow{2}{*}{$\begin{array}{l}\text { Dispensing without } \\
\text { prescription }\end{array}$} & Yes & 0 & 172 \\
\hline & No & 19 & 19 \\
\hline \multicolumn{2}{|l|}{$P$-value } & \multicolumn{2}{|l|}{0.098} \\
\hline \multirow{2}{*}{$\begin{array}{l}\text { Dispensing medicines on } \\
\text { older prescriptions }\end{array}$} & Yes & 2 & 170 \\
\hline & No & 17 & 21 \\
\hline \multicolumn{2}{|l|}{$P$-value } & 0.105 & \\
\hline \multirow{2}{*}{$\begin{array}{l}\text { Dispensing alternative brands } \\
\text { in case of nonavailability of } \\
\text { prescribed brand }\end{array}$} & Yes & 17 & 0 \\
\hline & No & 2 & 191 \\
\hline \multicolumn{2}{|l|}{$P$-value } & \multicolumn{2}{|l|}{0.000} \\
\hline \multirow{2}{*}{$\begin{array}{l}\text { Expiry date confirmation } \\
\text { before dispensing }\end{array}$} & Yes & 19 & 66 \\
\hline & No & 0 & 125 \\
\hline \multicolumn{2}{|l|}{$P$-value } & \multicolumn{2}{|l|}{0.000} \\
\hline
\end{tabular}

\section{Discussion}

In the past century, pharmacy as a profession mostly included compounding. While the compounding roles have declined considerably in the last few decades, it has turned out primarily to be dispensing medications. Nevertheless, merely dispensing 
of medications does not satisfy the necessities, and not long ago, a new role had to be progressed for the profession $[18,19]$. The aim of the pharmacy practice is to offer medicine in addition to further healthcare products and facilities, and to benefit people and community to make the best use of them [20]. Pharmacists need to be part of clinical decision-making for sensible use of medications. The transforming position of pharmacist as patient counsellor/instructor as well as an intermediary to enhance therapy outcome is important for encouraging reasonable use of medications [21]. The system by which medications are procured, stored, distributed, as well as dispensed and information provided by pharmacist determines the quality use, consequently in terms of motivating rational practice of medications [22].

In our study, it has been observed that only $9 \%$ of the pharmacists were present in various pharmacies. Rest of the pharmacies/medical stores had unqualified personals including personals who never attended school or those who had studied only till the eighth grade or had attended secondary or higher secondary school. Others had a professional education and single study participant was a qualified postgraduate. A study reports that generally qualification, understanding, and schooling of drug dispensers functioning at community drugstores in Pakistan is deficient. Pharmacies are mostly run by unqualified as well as inexpert personals. However, it has been noticed that they have copious years of experience [23]. Similar findings have been observed in our study that although majority of pharmacies had unqualified personals, they had plenty of experience. The existence of legitimately competent individuals is insignificant at drugstores. In majority of circumstances proprietors are operating instead of a trained individual [24]. However, in our study, it was observed that $74.3 \%$ of the participants were employee working in the pharmacy while $25.7 \%$ were the owner of the pharmacy.

According to the drug acts of Pakistan, pharmacy buildings must have suitable facilities to store drugs including refrigeration, cleanliness of outlets, hygienic and neat condition, and constant personal observation of a pharmacist [25]. However, in our study, it was revealed that majority of pharmacies did not took necessary measures for proper storage of medicines. Medicines are not stored in hygienic conditions and appropriate temperature was not maintained. Very few drugstores had power backup for refrigerator, which is a major distress as a consequence of extreme occurrence of power breakdown in city. These customs uncover that generally society is unaware or ignorant with regard to storage medications. In a related study from Karachi, greater than half of the pharmacies stored medications in compromised storage settings $[14,15,26,27]$.

Moreover, it was found in our study that $44.8 \%$ of the pharmacies had a valid pharmacy license, while $55.2 \%$ did not. However, it has been reported in a study that while $62.4 \%$ 
of the participants had a license for retail sale, only $5.6 \%$ of them were license holder for wholesale. Another one-fourth of the total drug sellers (26.9\%) were those having no license at all. Moreover, only $5.1 \%$ of the participants possessed license for the sale of controlled substances. But a total of $66 \%$ drug sellers were involved in selling of controlled substances [28].

About $81.9 \%$ of the study participants admitted selling medicines without prescription. Similarly, $81.9 \%$ of them admitted selling medicines on older prescriptions too. Moreover, a study from Rawalpindi reported that almost $16 \%$ of the study participants disclosed that they dispense medication even without prescription, however, this might be an underestimate, considering that it disregards acceptable practices [15]. This has greatly to do with the reality that regulations concerning drug dispensing are not appropriately enforced, and drugstores are unrestricted to dispense medicines deprived of prescriptions. Medication categories dispensed without prescription included OTC (41.4\%), antibiotics (16.7\%), analgesics (6.2\%), antidiabetic (5.7\%), anti-allergy (5.2\%), antidiarrheal (3.3\%), cough syrups (7.1\%), antihypertensive (4.3\%), and others (10\%). Similar findings have been reported in other studies in which it was reported that analgesics, antibiotics, antidiarrheal agents, antihistamines, antipyretics, cough-suppressants, "tonics," and vitamins are readily available without prescription from community pharmacies in Pakistan [29-33].

\section{Conclusion}

Medical stores/pharmacies of South Karachi surveyed in this study demonstrated poor dispensing practice. The structure and services do not meet the standards of WHO regarding medication-dispensing practice. The education level/qualification of dispensers is also questionable. The consequence of unsatisfactory procedures for medication dispensation can have damaging effects on public health and, for itself, those stores warrant great attention of public health researchers. There is a strong need for the implementation of laws and regulations in their full spirit. Persistent inappropriate use of medicine among the population living in the region of the study indicates a strong need for public education on the appropriate use of medicine via educational interventions and awareness seminars. 


\section{Acknowledgements}

The authors acknowledge the supporting staff and faculty members who guided them throughout the research process.

\section{Ethical Considerations}

The study was approved by the advance studies and research board of University of Sindh Jamshoro, Pakistan. Verbal as well as written informed consents were taken from respondents after concise introduction to study.

\section{Competing Interests}

The authors have no conflicts of interest to declare.

\section{Availability of Data and Material}

All relevant data and methodological detail pertaining to this study are available to any interested researcher upon reasonable request to corresponding author.

\section{Funding}

None.

\section{References}

[1] Alam, S., Osama, M., Iqbal, F., et al. (2018). Reducing pharmacy patient waiting time. International Journal of Health Care Quality Assurance, vol. 31, no. 7, pp. 834-844.

[2] Paulino, E., Thomas, D., Lee, S. W., et al. (2019). Dispensing process, medication reconciliation, patient counseling, and medication adherence. In D. Thomas (Ed.), Clinical Pharmacy Education, Practice and Research (pp. 109-120). Science Direct.

[3] Zafar, S. N., Syed, R., Waqar, S., et al. (2008). Self-medication amongst university students of Karachi: prevalence, knowledge and attitudes. Journal of the Pakistan Medical Association, vol. 58, no. 4, p. 214.

[4] Ullah, H. A., Khan, S. A., Ali, S., et al. (2013). Evaluation of self-medication amongst university students in Abbottabad, Pakistan: prevalence, attitude and causes. Acta 
Poloniae Pharmaceutica, vol. 70, no. 5, pp. 919-922.

[5] Hussain, A. and Khanum, A. (2008). Self-medication among university students of Islamabad, Pakistan-a preliminary study. Southern Med Review, vol. 1, no. 1, pp. $14-16$.

[6] Ahmed, B., Nanji, K., Mujeeb, R., et al. (2014). Effects of polypharmacy on adverse drug reactions among geriatric outpatients at a tertiary care hospital in Karachi: a prospective cohort study. PLoS ONE, vol. 9, no. 11, p. e112133.

[7] Sabzwari, S. R., Qidwai, W., and Bhanji, S. (2013). Polypharmacy in elderly: a cautious trail to tread. Journal of Pakistan Medical Association, vol. 63, no. 5, p. 624.

[8] Zaidi, S., Bigdeli, M., Aleem, N., et al. (2013). Access to essential medicines in Pakistan: policy and health systems research concerns. PloS ONE, vol. 8, no. 5, p. e63515.

[9] Hafeez, A., Kiani, A. G., Din, S. U., et al. (2004). Prescription and dispensing practices in public sector health facilities in Pakistan-survey report. Journal of Pakistan Medical Association, vol. 54, no. 4, pp. 187-191.

[10] Hussain, A., Malik, M., and Toklu, H. Z. (2013). A literature review: pharmaceutical care an evolving role at community pharmacies in Pakistan. Pharmacology \& Pharmacy, vol. 4 , no. 05, p. 425.

[11] Atif, M., Ahmad, M., Saleem, Q., et al. (2017). Pharmaceutical policy in Pakistan. In Z. Babar (Ed.), Pharmaceutical Policy in Countries with Developing Healthcare Systems (pp. 25-44). Adis, Cham.

[12] Khalid, L., Mahsood, N., and Ali, I. (2016). The public health problem of OTC antibiotics in developing nations. Research in Social and Administrative Pharmacy, vol. 12, no. 5, pp. 801-802.

[13] Haseeb, A. and Bilal, M. (2016). Prevalence of using non prescribed medications in economically deprived rural population of Pakistan. Archives of Public Health, vol. 74 , no. 1 , p. 1.

[14] Rabbani, F., Cheema, F. H., Talati, N., et al. (2001). Behind the counter: pharmacies and dispensing patterns of pharmacy attendants in Karachi. Journal of the Pakistan Medical Association, vol. 51, no. 4, p. 149.

[15] Butt, Z. A., Gilani, A. H., Nanan, D., et al. (2005). Quality of pharmacies in Pakistan: a cross-sectional survey. International Journal for Quality in Health Care, vol. 17, no. 4, pp. 307-313.

[16] World Health Organization. (1993). How to Investigate Drug Use in Health Facilities: Selected Drug Use Indicators. Geneva: World Health Organization. 
[17] Bhurgri, Y., Rahim, A., Bhutto, K., et al. (1998). Incidence of carcinoma of the oral cavity in Karachi-District South. Journal of the Pakistan Medical Association, vol. 48, no. 11, pp. 321-324.

[18] Caamaño, F., Ruano, A., Figueiras, A., et al. (2002). Data collection methods for analyzing the quality of the dispensing in pharmacies. Pharmacy World and Science, vol. 24, no. 6, pp. 217-223.

[19] Toklu, H., Akıcl, A., Oktay, Ş., et al. (2010). The pharmacy practice of community pharmacists in Turkey. Marmara Pharmaceutical Journal, vol. 14, no. 1, pp. 53-60.

[20] Stone, L. (1998). Good Pharmacy Practice in Developing Countries: Recommendations for Step-wise Implementation. Hague: FIP Congress Report.

[21] Caamaño, F., Álvarez, R., and Khoury, M. (2008). The community pharmacists and their practice as health care providers. Gaceta Sanitaria, vol. 22, no. 4, p. 385.

[22] Hussain, A. and Ibrahim, M. I. (2011). Medication counselling and dispensing practices at community pharmacies: a comparative cross sectional study from Pakistan. International Journal of Clinical Pharmacy, vol. 33, no. 5, p. 859.

[23] Hussain, A. and Ibrahim, M. I. (2011). Qualification, knowledge and experience of dispensers working at community pharmacies in Pakistan. Pharmacy Practice, vol. 9, no. 2, p. 93.

[24] Oun, S., Edward-Raj, A., Ojuola, O., et al. (2005). Assessing the quality of health services provided by informal drug sellers in rural Cambodia. In American Public Health Association 133rd Annual Meeting \& Exposition (pp. 10-14). Philadelphia.

[25] Ali, S. A., Ali, S. A., and Suhail, N. (2016). Importance of storing medicines on required temperature in pharmacies and role of community pharmacies in rural areas: literature review. i-Manager's Journal on Nursing, vol. 6, no. 2, p. 32.

[26] Shah, S. S., Naqvi, B. S., Fatima, M., et al. (2016). Quality of drug stores: storage practices \& regulatory compliance in Karachi, Pakistan. Pakistan Journal of Medical Sciences, vol. 32, no. 5, p. 1071.

[27] Aslam, N., Bushra, R., and Khan, M. U. (2012). Community pharmacy practice in Pakistan. Archives of Pharmacy Practice, vol. 3, no. 4, p. 297.

[28] Ullah, H., Zada, W., Khan, M. S., et al. (2016). Assessment of practice at retail pharmacies in Pakistan: extent of compliance with the prevailing drug law of Pakistan. Acta Poloniae Pharmaceutica, vol. 73, no. 3, p. 803.

[29] Arshad, M. S., Ijaz, M. F., and Hussain, A. (2010). Evaluation of antibiotic use behavior in cold and flu amongst the students of Bahauddin Zakariya University Multan Pakistan. Pakistan Journal of Pharmacy, vol. 23, no. 2, pp. 15-22. 
[30] Hussain, S., Malik, F., Hameed, A., et al. (2010). Exploring health seeking behavior, medicine use and self-medication in urban and rural Pakistan. Southern Med Review, vol. 3, no. 2, pp. 32-35.

[31] Khan, H., Maheen, S., Alamgeer, G. A., et al. (2014). Determinants of increasing trend of self-medication in a Pakistani community. Tropical Journal of Pharmaceutical Research, vol. 13, no. 3, pp. 437-443.

[32] Aqeel, T., Shabbir, A., Basharat, H., et al. (2014). Prevalence of self-medication among urban and rural population of Islamabad, Pakistan. Tropical Journal of Pharmaceutical Research, vol. 13, no. 4, pp. 627-633.

[33] Shaikh, B. T. and Hatcher, J. (2005). Complementary and alternative medicine in Pakistan: prospects and limitations. Evidence-Based Complementary and Alternative Medicine, vol. 2, no. 2, pp. 139-142. 